\title{
Ensino do verbo gustar em espanhol para brasileiros: intervenção pedagógica baseada na instrução de processamento
}

\author{
Teaching the verb gustar in Spanish for Brazilians: pedagogical intervention \\ based on the processing instruction
}

Elena Ortiz Preuss ${ }^{1}$

Doutora em Estudos da Linguagem, Especialidade em Linguística Aplicada, pela UFRGS (2011) Realizou estágio de pós-doutoramento no Departamento de Espanhol e Português da Georgetown University (2013). Professora do Programa de PósGraduação em Letras e Linguistica da UFG. Membro do Laboratớrio de Bilinguismo e Cognição, da vendo a pesquisa 'Condicões pedagógicas varíveis individuais na aquisicão pedagógicas E-mail: elena.ortizp@yahoo.com.br
RESUMO: Este artigo apresenta uma pesquisa que visou analisar efeitos da instrução de processamento (VANPATTEN, 2005), na aprendizagem do verbo gustar, por aprendizes brasileiros de espanhol. Essa instrução se baseia em processos psicolinguísticos que subjazem à compreensão do input, observando as estratégias naturais de processamento e suas convergências e divergências com o sistema-alvo da aquisição. Nessa perspectiva, preparamos uma sequência de atividades nas quais a atenção dos aprendizes foi manipulada durante o processamento do input para facilitar o intake e 0 estabelecimento de conexões entre forma e significado. A pesquisa foi desenvolvida com aprendizes, em nível inicial, divididos entre grupo experimental e controle. Na primeira parte do estudo, os grupos realizaram pré e pós- teste, contendo tarefas de julgamento de gramaticalidade, de identificação do sujeito das frases e de produção de frases, intercalados pelo período de instrução de processamento, aplicada somente ao grupo experimental Na segunda parte, o grupo experimental recebeu também a instrução tradicional (que prevê produção da estrutura-alvo) sobre o verbo gustar e realizou outro pós-teste. Os resultados não evidenciaram diferenças significativas entre os grupos, mas mostraram que a instrução de processamento aliada à instrução tradicional pode trazer benefícios ao processo de aquisição e uso da estrutura-alvo, pois torna a aprendizagem mais eficaz. Palavras-chave: Gustar; Input; Instrução de processamento.

ABSTRACT: This article presents a research which focused on analyzing the effects of processing instruction (VANPATTEN, 2005) when Brazilian learners of the Spanish language are trying to acquire the verb gustar. This instruction is based on the psycholinguistic processes that underlie the understanding of the input, observing the natural processing strategies and their convergences and divergences with the target system of the acquisition. We had prepared activities in which the learners' attention was manipulated during input processing to facilitate the intake and the establishment of connections between form and meaning. The research was developed with beginner learners, divided between experimental and control group. In the first part of the study, the groups performed pretests and posttests containing grammaticality judgment tasks, subject identification and the production. Those procedures were interspersed by the period of processing instruction and applied only to the experimental group. In the second part, the experimental group also received the traditional instruction (which predicts a target structure production) and performed another posttest. Although the results have not shown significant differences between the groups, they have shown that the processing instruction allied to the traditional instruction can bring benefits to the acquisition and use of the target structure, because it makes learning more effective. Keywords: Gustar; Input; Processing instruction. 


\section{Introdução}

0.min estabelecimento de conexões entre forma e significado de frases com o verbo "gostar" (gustar) em espanhol, embora seja um conteúdo abordado desde os níveis mais iniciais de aprendizagem ${ }^{1}$, é bastante complexo ao aprendiz brasileiro (ABIO, 2008), provavelmente, devido a razões sistêmicas e cognitivas. Na perspectiva sistêmica, destacam-se diferenças sintáticas e semânticas entre espanhol e português. Sintaticamente, em espanhol, o verbo "gostar" costuma seguir a estrutura não canônica OVS, ou seja, objeto-verbo-sujeito (CAMPOS, 2000; DELBECQUE e LAMIROY, 2000), e semanticamente, aquele que experimenta o estado psicológico/sensação de gostar (experienciador) é o objeto indireto, não o sujeito sintático², como em português. Na perspectiva cognitiva, baseando-se no modelo de processamento do input ${ }^{3}$, proposto por VanPatten (2005), qualquer aprendiz de segunda língua (doravante $\mathrm{L} 2)^{4}$ tende, naturalmente, a processar o primeiro nome ou pronome como sendo o sujeito da frase. Ademais, nos estágios mais iniciais, frequentemente, os aprendizes tendem a se apoiar na sua primeira língua (doravante L1), o que potencializa a ocorrência de fenômenos de interferência interlinguística (ELLIS, 2012; ORTEGA, 2013; ORTIZ-PREUSS e SANZ, 2016).

Para ilustrar melhor, tomamos como exemplo o seguinte caso: $\mathrm{o}$ aprendiz tende a interpretar a expressão em espanhol "Ana me gusta" como sendo "Ana gosta de mim" em português, entretanto, embora o sintagma nominal

1 Neste artigo as palavras aprendizagem e aquisição são usadas como sinônimos.

2 Cabe esclarecer que, neste estudo, a diferença entre sujeito sintático e sujeito semântico é que o primeiro se refere, exclusivamente, ao determinante da estrutura sintática que estabelece concordância com o núcleo do predicado, e o segundo se refere às propriedades semânticas do argumento, como, por exemplo, ser agente ou paciente da ação verbal.

exemplo, ser agente ou paciente da ação verbal.
3 Refere-se à amostra linguística à qual o aprendiz é exposto.

4 Usamos a sigla L2 no lugar do termo segunda língua, e abrangendo também a concepção de língua estrangeira.
"Ana" funcione como sujeito sintático nas duas frases, semanticamente, há distinções entre as línguas. Enquanto no português, trata-se de um sujeito experienciador, no espanhol, "Ana" se refere à causa de gostar. Em vista disso, a sentença em espanhol seria, de fato, equivalente a "Eu gosto da Ana", em português.

Por outro lado, considerando-se alguns princípios do modelo de processamento do input, VanPatten $(1996,2002,2005)$ propôs a instrução de processamento, que é um tipo de intervenção pedagógica com foco na forma, fundamentada nos processos psicolinguísticos e cognitivos que subjazem à compreensão do input na L2. Trata-se de um tipo de instrução que leva em consideração estratégias de processamento usadas pelos aprendizes e visa a facilitar o intake $e^{5}$, bem como o mapeamento forma-significado.

Em vista do exposto, desenvolvemos uma pesquisa com o propósito de verificar os efeitos da instrução de processamento no ensino do verbo "gostar" a aprendizes brasileiros de espanhol, para uma aprendizagem mais eficaz e adequada dessa estrutura linguística. Neste artigo, faremos uma breve exposição sobre as diferenças envolvendo a estrutura e funcionamento do verbo-alvo deste estudo (gostar) em português e espanhol, e apresentaremos alguns princípios do modelo de processamento do input que fundamentam a instrução de processamento. A partir da exposição do referencial teórico, procederemos à exposição dos procedimentos metodológicos adotados, às análises de dados e às discussões dos resultados. Por último, teceremos algumas considerações finais sobre os principais resultados obtidos e as contribuições deste estudo para a área de ensino-aprendizagem de espanhol como L2.

5 De acordo com VanPatten (2005), intake se refere aos dados linguísticos que são processados mantidos na memória de (rabaht, ño sendo mantidos na memória de trabalho, não sendo equivalente à forma linguística adquirida; trata-se de a compreensão online e que não necessariamente se torna representação mental na L2" (op. cit. p. 271). 


\section{Fundamentação Teórica}

\subsection{Estrutura e funcionamento do verbo gustar em espanhol e português}

O funcionamento da estrutura sintática do verbo "gostar" (gustar) em espanhol é bastante diferente do português. Na oração "Me gustan las frutas" (Eu gosto de frutas), por exemplo, observe-se que a estrutura preferencial na língua é a não canônica OVS, isto é, objeto indireto (me), verbo (gustan) e sujeito (las frutas) ${ }^{6}$ (CAMPOS, 2000; DELBECQUE e LAMIROY, 2000). Em português, por outro lado, o sintagma "as frutas" é o objeto do verbo, cujo sujeito é o pronome "eu". Isso evidencia distinções, de natureza sintáticosemântica, entre as línguas no uso do verbo "gostar".

Os verbos psicológicos, como o verbo "gostar", são uma categoria verbal caracterizada por expressar estados emocionais e envolver dois argumentos ${ }^{7}$, os quais indicam quem sofre o estado mental, bem como a sua causa ${ }^{8}$. Esses argumentos podem receber diferentes papéis temáticos ${ }^{9}$, dependendo de sua

${ }^{6}$ A expressão "Las frutas me gustan" também é possível embora menos frequente em espanhol. De acordo com Delbecque; Lamiroy (2000), em frases com verbos como "gostar", o sujeito oracional costuma ir posposto ao verbo, sendo mais frequente a ordem OVS. Campos (2000, p. 1560) também esclarece que "quando o sujeito precede ao verbo nestas construções, o sujeito parece focalizado" (cuando el sujeto precede al verbo en estas construcciones, el sujeto parece focalizado).

Seguindo os pressupostos da gramática gerativa, o verbo "gostar" estabelece uma relação semântica de gosto entre dois elementos: o que provoca o estado mental e o que o experimenta. Isto é, o verbo "gostar" deixa duas lacunas a serem preenchidas pelos seus complementos: 1) quem gosta, e 2) de quê ou de quem gosta. Por essa razão, considera-se que este verbo possui dois argumentos (MIOTO; SILVA e LOPES, 2004)

8 Essa definição de verbos psicológicos vale para português e espanhol.

9 Papel temático se refere a aspectos do significado do verbo envolvendo o tipo de relação semântica dos seus argumentos. Por exemplo, um verbo transitivo como "cortar", requer que alguém corte alguma coisa, em vista disso, na frase "Ana cortou o bolo", "cortar" possui um argumento agente (quem pratica a ação - Ana) e um paciente (quem recebe a ação - o bolo) (SOARES e MENUZZI, 2010). Há vários tipos de papéis temáticos que os argumentos podem receber, dentre eles: agente, tema, experienciador de papéis temáticos que os argumentos podem receber, dentre eles: agente, tema, experienciador benefactivo, locativo, etc. Devido ao escopo deste trabalho, que nos impossibilita aprofundar essa discussão, sugerimos ao leitor interessado, o artigo "Introduzindo e problematizando papéis temáticos de Mioto, Silva e Lopes (2004) ou a sua edição mais nova de 2013. função semântica no predicado, como, por exemplo, ser o experienciador, isto é, aquele que experimenta o estado psicológico, ou ser o tema ou causa desse estado. Quanto à estrutura sintática, é importante mencionar que o experienciador pode aparecer ou na posição de sujeito ou na posição de complemento verbal (CANÇADO, 2012; COLUCCIELLO, 2015).

Em espanhol, o verbo "gostar" expressa um estado emocional causado por um sujeito, cujo objeto é expresso por um pronome de objeto indireto que pode estar acompanhado pelo respectivo complemento lexical (DELBECQUE; LAMIROY, 2000). De acordo com Campos (2000), em orações com verbos psicológicos, o complemento indireto costuma preceder o verbo e isso não é considerado um caso de topicalização do objeto indireto. Portanto, em espanhol, a estrutura sintática preferencial de orações envolvendo verbos psicológicos como o verbo "gostar" é a OVS, e em termos semânticos, o objeto indireto é o experienciador, e o sujeito é o tema/motivo do estado psicológico. Para exemplificar, sintetizando o exposto até aqui, observemos a frase “( A ti $)^{10}$ te gusta este libro" (Tu gostas deste livro), analisada no Quadro 1:

Quadro 1 - Estrutura sintático-semântica do verbo "gostar" em espanhol

\begin{tabular}{|c|c|c|}
\hline Constituintes da frase & Perspectiva sintática & Perspectiva semântica \\
\hline (A ti) te & objeto indireto & experienciador \\
\hline gusta & verbo & verbo \\
\hline este libro & sujeito & tema \\
\hline
\end{tabular}

Em português, por outro lado, os verbos psicológicos apresentam o experienciador como sujeito sintático da frase e o tema como objeto (CANÇADO, 2012). Isto é, com essa categoria verbal, em português, o sujeito

${ }^{10} \mathrm{~A}$ estrutura "A ti" está entre parênteses, pois a duplicação do complemento indireto nem sempre obrigatória na frase, havendo contextos em que o grupo preposicional que integra o complemento indireto é opcional (RAE, 2010). 
é quem sofre o estado mental e não o motivo desse estado. Além disso, a ordem da estrutura sintática preferencial é a canônica SVO (sujeito-verboobjeto). Observe-se a análise no Quadro 2, referente à frase "Elas gostam de café".

Quadro 2 - Estrutura sintático-semântica do verbo "gostar" em português

\begin{tabular}{|c|c|c|}
\hline Constituintes da frase & Perspectiva sintática & Perspectiva semântica \\
\hline Elas & sujeito & experienciador \\
\hline gostam & verbo & verbo \\
\hline de café & objeto & tema \\
\hline
\end{tabular}

Em suma, as distinções de usos do verbo "gostar" em português e espanhol se devem a diferenças: a) na estrutura sintática, enquanto no espanhol a ordem não canônica é mais frequente, no português predomina a ordem SVO; e b) na estrutura semântica, porque o sujeito é o motivo (tema) do estado mental, em espanhol, enquanto no português o sujeito é quem sofre/experimenta (experienciador) o estado mental. Essas distinções podem gerar dificuldades no processo de aprendizagem do verbo "gostar" em aprendizes brasileiros de espanhol, se eles tentarem se apoiar na sua L1 para expressar-se na L2, como expusemos anteriormente. Além disso, como veremos na próxima seção, segundo os princípios de processamento do input, os aprendizes tendem, naturalmente, a processar o primeiro nome ou pronome da sentença como sujeito da frase (VANPATTEN, 1996, 2002, 2005), tornando a estrutura preferencial do verbo "gostar", em espanhol, ainda mais difícil a esses aprendizes.

\subsection{Processamento do input}

Conforme VanPatten (1996, 2002, 2005), o processamento do input se refere ao modo como o aprendiz obtém intake, independente da língua-alvo e do contexto de exposição. A partir de uma perspectiva cognitivista que pressupõe uma capacidade limitada de atenção e de Memória de Trabalho ${ }^{11}$ (doravante MT) (FINGER e ORTIZ-PREUSS, 2009; SANZ, 2005; SCHMIDT, 2001), o foco do modelo de processamento do input é nas conexões formasignificado estabelecidas pelos aprendizes de L2. Em outras palavras, aborda o comportamento desses aprendizes ao processar as estruturas formais das sentenças ao mesmo tempo em que seu foco atencional está centrado no significado. Conforme o modelo, a capacidade de processamento da informação é limitada, porque a funcionalidade da MT depende da disponibilidade de recursos atencionais. Quando o sistema atencional é sobrecarregado, a MT deve ser esvaziada para que novas informações possam ser temporariamente retidas (VANPATTEN, 2005).

O modelo de processamento do input, proposto por VanPatten (1996, 2002, 2005), consiste numa série de princípios e proposições que levam em consideração o desempenho desses sistemas cognitivos. VanPatten (2005, p. 268-269) ${ }^{12}$ resumiu o conjunto de princípios de processamento do input, como segue:

1. Primazia do significado: os aprendizes processam o significado antes da forma.

a) Primazia das palavras de conteúdo: o processamento das palavras de conteúdo ocorre antes de qualquer outro item.

b) Preferência lexical: os aprendizes tenderão a contar com itens lexicais em oposição às formas gramaticais para obter significado, quando ambos codificam a mesma informação semântica.

c) Preferência por não redundância: o processamento de formas gramaticais significativas não redundantes é anterior às redundantes.

d) Significado antes do não significado: o processamento de formas gramaticais significativas é anterior às não significativas independente da redundância.

${ }^{11}$ Trata-se de um sistema de gerenciamento que retém e manipula informação para a realização de tarefas. Para mais informações sugere-se a leitura de Baddeley, Anderson e Eysenck (2011)

12 Tradução e adaptação nossa. 
e) Disponibilidade de recursos: para que os aprendizes processem formas gramaticais significativas (não) redundantes, o processamento do significado sentencial geral não deve esgotar os recursos de processamento disponíveis.

f) Localização da sentença: os aprendizes tendem a processar itens na posição inicial da sentença antes daqueles em posição final e medial.

2. Primeiro nome: os aprendizes tendem a atribuir papel de sujeito ou agente ao primeiro (pro)nome/substantivo que aparece na sentença.

a) Semântico lexical: a semântica lexical de verbos pode atenuar a confiança no princípio de primeiro nome.

b) Probabilidade eventual: a confiança no princípio de primeiro nome pode ser diminuída pelas probabilidades eventuais.

c) Restrição contextual: os aprendizes podem confiar menos no princípio de primeiro nome se restrições contextuais precedem a interpretação possível da sentença.

De acordo com esses princípios, o sistema de atenção fica dividido entre os traços linguísticos formais e o significado das sentenças. 0 processamento linguístico on-line, ou seja, em tempo real, ocorre de maneira rápida e automática, fundamentando-se em algumas estratégias ${ }^{13}$, como por exemplo: priorizar palavras de conteúdo e não redundantes, evitar esgotar os recursos disponíveis no processamento geral da sentença, e focar a atenção em partes distintas da sentença (enfocando os itens iniciais, finais e por último os intermediários).

$\mathrm{O}$ autor exemplifica o modelo com as seguintes frases (VANPATTEN, 2005, p. 270) ${ }^{14}$

(1) Ontem meus pais ligaram para me dizer algo importante.

(2) Onde estudaste?

${ }^{13}$ Ao ler uma frase, não precisamos decodificar cada uma de suas partes (fonemas, morfemas e palavras) para conseguir compreendê-la. Além disso, posteriormente, lembramos-nos do sentido expressado, não das palavras que foram usadas na frase.

não das palavras que
${ }_{14}^{14}$ Traduções nossas.
Na frase (1), a temporalidade, indicando tempo passado, é expressa na palavra ontem (advérbio) e na flexão verbal (-aram). Em vista disso, e seguindo o princípio 1b (preferência lexical), o aprendiz pode captar essa informação no advérbio, ignorando a conjugação do verbo ligar. A ideia de pluralidade também é duplamente marcada na frase, pelo sintagma nominal "meus pais" e pela flexão verbal (-aram), assim, novamente, os aprendizes não precisam estar atentos à conjugação verbal para compreenderem que se trata de um sujeito no plural. Conforme o exposto, a flexão verbal na frase pode ser considerada uma forma redundante e não significativa e, muito provavelmente, o aprendiz demorará mais para focar sua atenção nela.

Na frase (2), pelo contrário, a flexão verbal não é redundante e é bastante significativa, pois é a única forma na sentença que faz referência ao tempo (passado) e ao sujeito ("-aste" é o morfema de número-pessoa correspondente a "tu"). Nesse caso, o aprendiz precisa prestar atenção na morfologia verbal para alcançar a completude da compreensão da sentença.

De acordo com o exposto, abordamos, neste estudo, as implicações do princípio 2 no processamento de línguas que usam a ordem estrutural não canônica (OVS), como no caso do verbo "gostar" em espanhol. Numa frase como A ella le gusta bailar (Ela gosta de dançar), ao aplicar-se o princípio do primeiro nome, o aprendiz pode processar o pronome "ella" como sendo o sujeito da frase, quando de fato se refere ao objeto indireto, como vimos anteriormente. Em vista disso, VanPatten (1996, 2002, 2005) propõe um tipo de intervenção pedagógica denominada de instrução de processamento, a qual visa a ajudar ao aprendiz a usar estratégias de processamento mais adequadas. Na próxima seção, descreveremos essa proposta de ensino.

\subsection{Instrução de processamento}

De acordo com VanPatten (1996, 2002, 2005), a instrução de processamento pretende auxiliar no estabelecimento de conexões entre forma 
e significado, através da manipulação de dados do input e da atenção do aprendiz, durante o processamento de sentenças. 0 pressuposto é o de que, considerando o modo de processamento de informações, pode ser possível facilitar o intake dos aprendizes. Em outras palavras, refere-se a um tipo de intervenção pedagógica com foco na forma ${ }^{15}$, baseada em processos psicolinguísticos que ocorrem enquanto o aprendiz compreende o input na L2.

A instrução de processamento difere de outras abordagens baseadas no input (saliência do input; recasts; input flood, etc. ${ }^{16}$ ) porque nesse tipo de intervenção não se prevê a produção da forma-alvo. A instrução de processamento se realiza na fase de compreensão, requerendo que o aprendiz processe a sentença e a interprete corretamente enquanto presta atenção à forma. Dentre as características básicas da instrução de processamento, VanPatten $(2005)^{17}$ menciona que os aprendizes:

1. recebem informação sobre a estrutura linguística (forma).

2. recebem informação sobre estratégias de processamento do input que podem afetar sua aquisição da forma durante a compreensão.

3. são levados a processar a forma durante as atividades com input estruturado ${ }^{18}$ - que é manipulado para que o aprendiz considere a forma para chegar ao significado (ou seja, são afastados de sua tendência natural de processamento para uma estratégia mais eficiente).

O autor (op. cit.) explica que o input estruturado, fornecido na instrução de processamento, pode ser de dois tipos: referencial e afetivo. 0 input

${ }^{15} \mathrm{~A}$ concepção de foco na forma que pressupõe essa intervenção é a que defende o direcionamento da atenção a determinados aspectos do input aos quais, sozinho, o aprendiz poderia não conseguir (DOUGTHY e WILLIAMS, 1998; ELLIS, 1998, 2005, 2012).

${ }^{16}$ Essas abordagens do input se referem, respectivamente: ao uso de destaque visual ou auditivo do input, às praticas de reformulação que o professor faz da fala do aluno e à oferta de grande quantidade de input com a estrutura-alvo. Ao leitor interessado, sugerimos a leitura de Dougthy e Williams (1998) e de Ellis $(1998,2005,2012)$

de Ellis (1998, 2005, 2012).
${ }^{17}$ Tradução e adaptação nossa.

${ }_{18}$ Trata-se de um tipo de intervenção pedagógica que manipula as amostras linguísticas às quais o aprendiz é exposto para direcionar sua atenção (ELLIS, 2005). estruturado referencial é mais controlado, pois o padrão de respostas é o mesmo para todos os aprendizes, e abrange atividades cujas respostas são do tipo sim/não ou certo/errado de acordo com alguma fonte de referência, seja uma gravação, seja um texto (como no exemplo (a)). 0 input estruturado afetivo é menos controlado, porque as respostas podem variar conforme as opiniões pessoais, crenças e posicionamentos mais subjetivos dos aprendizes, ou seja, envolve atividades de expressar opinião, crença ou qualquer tipo de resposta afetiva/pessoal (como no exemplo (b)). A seguir apresentamos alguns exemplos que criamos com foco no verbo "gostar", para ilustrar melhor tais conceitos ${ }^{19}$ :

(a) Instrução a ser dada aos estudantes: Ouça a gravação de um personagem falando sobre seus gostos pessoais. Em seguida, marque na ficha quais coisas ele disse que gosta e quais ele não gosta.

\begin{tabular}{|l|l|l|}
\hline & Sim & Não \\
\hline Viajar & & \\
\hline Ler & & \\
\hline Dançar & & \\
\hline
\end{tabular}

O professor deverá fazer perguntas oralmente sobre cada um dos itens (por exemplo: Ele gosta de viajar?) e os alunos somente respondem sim ou não.

(b ) Preencha a ficha com os seus gostos pessoais a respeito de cada item, marcando nas colunas correspondentes a sim e não. Depois, com a ajuda do seu professor identifique colegas que tenham os mesmos gostos que você.

${ }^{19}$ Cabe ressaltar que a principal diferença entre cada um dos tipos de input (referencial ou afetivo) é o nível de objetividade e subjetividade das respostas e que esses exemplos não representam as únicas formas de se oferecer cada um dos tipos de input estruturado. 


\begin{tabular}{|l|l|l|l|}
\hline & Sim & Não & Colega \\
\hline Filmes de ação & & & \\
\hline Estudar & & & \\
\hline Dançar & & & \\
\hline
\end{tabular}

O professor deverá orientar os alunos a identificarem os colegas com os mesmos gostos, a partir de suas respostas na atividade de socialização, na qual ele irá solicitar que os alunos levantem a mão para responder a perguntas, como: Levanta a mão quem marcou na ficha que gosta de estudar? E quem marcou que não gosta? Portanto, a atividade abrange um momento individual em que o aprendiz marca na ficha se gosta ou não, e outro momento em grupo em que o aluno deve prestar atenção à resposta de seus colegas para preencher a terceira coluna da ficha.

Cabe mencionar ainda que, segundo VanPatten (2005, p. 275) ${ }^{20}$, a elaboração de atividades de input estruturado deve seguir os seguintes critérios:

1. Uma forma de cada vez.

2. Manter o significado em foco.

3. Os aprendizes devem fazer algo com o input.

4. O input deve ser oral e escrito.

5. Ir da sentença ao discurso.

6. Manter em mente as estratégias de processamento do aprendiz.

De acordo com Cadierno (2010), cada um desses contempla a funcionalidade dos mecanismos de processamento de informação, cuja capacidade é limitada. 0 primeiro critério tem relação com o processamento do item linguístico. O segundo evidencia que não se deve fazer uso de exercícios mecânicos e descontextualizados. O terceiro critério aponta

${ }^{20}$ Tradução nossa. que o aprendiz deve estar envolvido de forma ativa nas atividades, sem necessariamente produzir a estrutura-alvo. 0 critério quatro se relaciona com a abrangência de diferentes estilos de aprendizagem. 0 critério cinco oportuniza mais tempo de processamento, quando a atenção é dirigida à determinada forma. E o último critério (6) aponta a necessidade de se evitar o uso de estratégias que impeçam o aprendiz de prestar atenção a determinado item linguístico. É importante destacar que, segundo VanPatten (2005), se a atividade não altera estratégias de processamento, então não é instrução de processamento, porque essa intervenção identifica as estratégias que podem ser problemáticas e fornece atividades que previnam seu uso pelos aprendizes.

É importante ressaltar que, a partir de um modelo de processamento da informação, a aquisição de L2 se desenvolve em pelo menos quatro etapas principais, começando pelo input, que se torna intake e depois pode se integrar ao sistema de interlíngua para, então, ser usado no output (produção), conforme a Figura 1:

Figura 1 - Processo de aquisição de L2

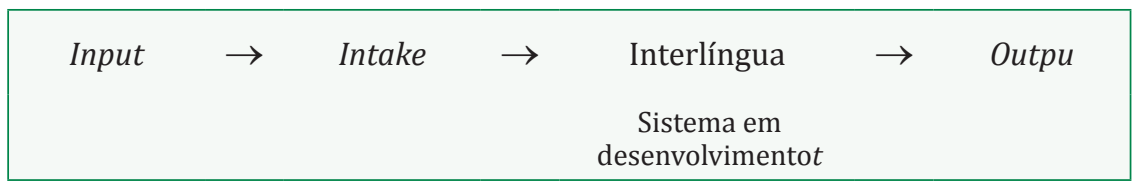

Fonte: Gass e Selinker (2008, p. 373).

De acordo com Gass e Selinker (2008), a instrução de processamento se diferencia de outros tipos de instrução tradicionais, pelo lugar em que ela se situa no processo de aquisição de L2 e pela sua ênfase nos mecanismos de processamento. Os autores (op.cit.) explicam que as instruções tradicionais priorizam a interlíngua e o output, porque suas práticas preveem produções 
com a estrutura-alvo, enquanto a instrução de processamento prioriza o input e o intake, pois suas atividades se concentram na fase de compreensão, como ilustra a Figura 2:

Figura 2 - Foco das instruções no processo de aquisição de segunda língua

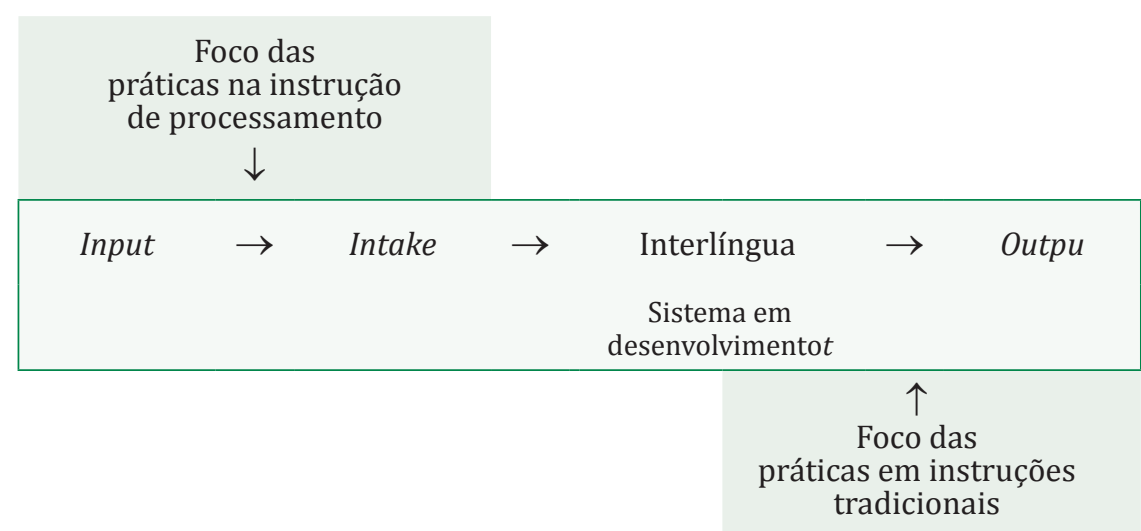

Fonte: Gass e Selinker (2008, p. 373).

Estudos na área de aquisição de segunda língua têm apontado evidências positivas para a instrução de processamento (CADIERNO, 2010; VANPATTEN, 2005), como, por exemplo, VanPatten e Cadierno (1993), VanPatten e Sanz (1995) e VanPatten e Oikkenon (1996), que pesquisaram a aquisição do posicionamento dos pronomes clíticos em espanhol/L2, por aprendizes estadunidenses, baseando-se no princípio do primeiro nome (tendência de se processar o primeiro nome ou pronome da sentença como sujeito); Cadierno (1995), que tratou da aquisição do pretérito perfeito em espanhol, também por aprendizes estadunidenses, baseando-se no princípio da preferência lexical (tendência de prestar mais atenção aos itens lexicais do que às formas gramaticais).
Nesses estudos, em geral, se pretendia comparar efeitos da instrução de processamento com a instrução tradicional, através de uma amostra dividida em 3 grupos $^{21}$ : um que recebia instrução de processamento (explicação gramatical e exercícios de compreensão e interpretação); um que recebia instrução tradicional (explicação gramatical e exercícios com produção); e um que não recebia nenhuma instrução. A avaliação da intervenção era feita por meio de pré e pós-teste, abrangendo atividades de compreensão, interpretação e produção ${ }^{22}$. Os resultados dessas pesquisas mostraram vantagens da instrução de processamento, inclusive na produção, embora essa abordagem não a enfoque. Os resultados também mostraram que a instrução tradicional somente se mostrou benéfica na produção.

Cabe mencionar que os estudos que enfocaram os pronomes clíticos foram feitos buscando responder a alguns questionamentos quanto à vantagem da instrução de processamento, apontada na primeira pesquisa, de VanPatten e Cadierno (1993). Já VanPatten e Sanz (1995) pretendiam verificar se os resultados obtidos em produções controladas seriam alcançados também em produções mais espontâneas, o que acabou se confirmando em sua pesquisa. Por sua vez, VanPatten e Oikkenon (1996), considerando que a instrução de processamento previa também explanação gramatical, buscaram identificar a origem das vantagens, isto é, se eram devido à abordagem de processamento do input ou à explicação gramatical. Em seu estudo, os três grupos estavam assim distribuídos: 1) grupo que recebeu instrução de processamento (input estruturado e instrução explícita ${ }^{23}$ ) sobre os pronomes em espanhol; 2) grupo que recebeu apenas

${ }^{21}$ O tipo de divisão de grupos no estudo de VanPatten e Oikkenon (1996) é diferente e será descrito posteriormente.

(2005), que previa somente atividades de interpretação e produção.

${ }^{23}$ Tipo de intervenção pedagógica em que se faz explanação sobre determinada estrutura linguística. Pode ser feita de modo indutivo ou dedutivo, sem necessariamente fazer uso de metalinguagem (ELLIS, 2005). 
input estruturado, sem explicação gramatical; e 3) grupo que recebeu somente instrução explícita. Estes pesquisadores constataram que somente os grupos que receberam input estruturado (o primeiro e o segundo grupos), seja com instrução explícita ou não evidenciaram progressos no pós-teste, mas o grupo que recebeu somente instrução explícita (o terceiro), sem input estruturado, não demonstrou mudança significativa do pré- ao pós-teste.

Mesmo tendo sido encontrados vários resultados favoráveis, a instrução de processamento também recebeu críticas (DEKEYSER, et al., 2002; ELLIS, 2012). Entretanto, VanPatten (2005) assegura que é o modelo de processamento do input que é criticado, devido à sua base psicolinguística e cognitiva, não à instrução de processamento em si. Ainda, de acordo com o autor (op. cit.), há pesquisas que têm buscado verificar se os efeitos dessa instrução são duradouros e generalizáveis a outras estruturas linguísticas, bem como se pode haver interação de diferentes componentes (como presença/ausência de explicação gramatical) nos resultados. Nesse escopo, insere-se o presente estudo, que tem como objetivo geral observar efeitos da instrução de processamento na aquisição do verbo "gostar" (em espanhol) por aprendizes brasileiros. Na próxima seção descreveremos o experimento realizado.

\section{Método}

\subsection{Participantes}

A pesquisa contou com 19 aprendizes brasileiros de espanhol, de nível inicial ${ }^{24}$, divididos em dois grupos. Um grupo, denominado experimental, estava composto por 8 participantes, sendo 5 do sexo feminino e 3 do sexo

${ }^{24}$ São participantes que estão no primeiro nível de seu curso de línguas, com aproximadamente dois meses de aula, o que totaliza uma média de 32 horas/aula. masculino, com média de idade de 24 anos. 0 segundo grupo, denominado controle, estava composto por 11 participantes, sendo 6 do sexo feminino e 5 do sexo masculino, com média de idade de 27,5 anos.

A participação era voluntária e, após esclarecimentos sobre os procedimentos da pesquisa, todos os participantes, que concordaram participar, assinaram o Termo de consentimento livre e esclarecido, conforme previsto no protocolo de pesquisa, aprovado pelo Comitê de Ética em Pesquisa da Universidade Federal de Goiás (CEP/UFG, sob o número CAAE 23328113.7.0000.5083).

A classificação dos grupos em experimental e controle segue uma razão exclusivamente logística. Como gostaríamos de aplicar pessoalmente a instrução de processamento, o grupo experimental foi aquele em que foi possível a substituição do professor, sem prejuízos ao processo de ensinoaprendizagem e com a concordância de todos os alunos, inclusive, daqueles que não aceitaram ser participantes da pesquisa.

\subsection{Procedimentos}

Para o grupo controle, o estudo previa somente duas etapas de testes (pré- e pós-teste), já que, por motivos operacionais ${ }^{25}$, não foi possível realizar o pós-teste 2. Este grupo não recebeu nenhum tipo de instrução sobre o verbo "gostar", o qual eles ainda não haviam estudado durante as etapas da pesquisa em que participaram.

Para o grupo experimental, o estudo consistiu em três etapas (pré-teste, pós-teste e pós-teste 2). No intervalo entre o pré- e o pós-teste, num período de duas aulas, de $1 \mathrm{~h}$ e 40 minutos cada, em dias diferentes, conseguimos com a professora desse grupo permissão para aplicarmos a instrução de

${ }^{25} \mathrm{O}$ grupo controle foi o grupo em que recebemos autorização para fazer as coletas de pré e pós-teste somente. 
processamento sobre o verbo "gostar", no momento em que ela ia iniciar o estudo dessa forma verbal. Depois da instrução de processamento e da aplicação do pós-teste, a professora seguiu o trabalho de intervenção pedagógica com o verbo "gostar", usando a instrução que chamamos aqui de tradicional, pois inclui explicação de regras e atividades de compreensão e de produção com a estrutura-alvo. Após a finalização do estudo do verbo "gostar" com o grupo, aplicamos o pós-teste 2. No Quadro 3, sintetizamos as etapas da pesquisa, descritas anteriormente:

Quadro 3 - Etapas da pesquisa

\begin{tabular}{|l|c|c|c|c|c|}
\hline \multicolumn{1}{|c|}{ Grupo } & \multicolumn{2}{|c|}{ Etapa 1 } & \multicolumn{2}{c|}{ Etapa 2 } & Etapa 3 \\
\hline Experimental & Pré-teste & $\begin{array}{c}\text { Instrução de } \\
\text { processamento }\end{array}$ & Pós-teste & $\begin{array}{c}\text { Instrução } \\
\text { tradicional }\end{array}$ & Pós-teste 2 \\
\hline Controle & Pré-teste & & Pós-teste & & \\
\hline
\end{tabular}

\subsection{Tarefas}

Os testes foram aplicados em formulários do Google Docs e cada um estava composto de três tarefas: 1) julgamento de gramaticalidade; 2) identificação do sujeito das frases; e 3) produção de frases.

A tarefa de julgamento de gramaticalidade, conforme o exemplo (c) a seguir, consistia em ler frases e dizer se eram gramaticais ou não. Havia 10 frases em cada teste, sendo 6 alvo e 4 distratoras.
(c) A ellas les gusta los deportes.
( ) gramatical ( ) agramatical Me gusta mucho la carne asada.
( ) gramatical ( ) agramatical

A tarefa de identificação do sujeito da frase, conforme o exemplo (d), consistia em ler frases e citar quem era o sujeito de cada uma. Havia 16 frases em cada teste, sendo 12 alvo e 4 distratoras.
(d) Le gustamos nosotras.
Sujeto: A ti te gustan mis amigos.
Sujeto:

Finalmente, a tarefa de produção, como no exemplo (e), consistia em produzir 5 frases com o verbo "gostar", usando os elementos dispostos em dois quadros: (e)

\begin{tabular}{|c|}
\hline (El que provoca la sensación) \\
- tú \\
- nosotros \\
- el fútbol \\
- ver la tele \\
- los tebeos
\end{tabular}

\begin{tabular}{|c|}
\hline (A quien se provoca la sensación) \\
- a mí \\
- a nosotras \\
$-a$ ellas \\
$-a$ usted \\
$-a$ vosotros
\end{tabular}

$$
1 .
$$

2

3

4.

5.

\subsection{Instrução de processamento}

Preparamos a instrução de processamento com o verbo gustar, procurando seguir as orientações explicitadas em VanPatten (2005). As atividades propostas estão descritas no Quadro 4 e foram desenvolvidas ao longo de dois encontros, de $1 \mathrm{~h}$ e 40 minutos, cada. 
Quadro 4 - Planejamento da instrução de processamento

\begin{tabular}{|c|c|c|}
\hline Passo & Tipo de input & Atividade \\
\hline 1 & Oral e escrito & $\begin{array}{l}\text { Ouvir a música } A \text { mí me gustan las hamburguesas e completar com } \\
\text { as palavras que faltam (nomes de comidas). }\end{array}$ \\
\hline 2 & Oral e escrito & $\begin{array}{l}\text { Atividade de compreensão leitora sobre a música (sem envolver a } \\
\text { produção do verbo-alvo). }\end{array}$ \\
\hline 3 & $\begin{array}{l}\text { Oral e escrito } \\
\text { Estruturado } \\
\text { referencial }\end{array}$ & $\begin{array}{l}\text { Completar um quadro com as comidas que o sujeito da música gosta } \\
\text { e não gosta (escrever somente o nome de cada comida no campo } \\
\text { respectivo - gosta/não gosta). }\end{array}$ \\
\hline 4 & $\begin{array}{l}\text { Oral e escrito } \\
\text { Estruturado } \\
\text { afetivo }\end{array}$ & $\begin{array}{l}\text { Numa conversa em grupo, os alunos deviam dizer se tinham os } \\
\text { mesmos gostos alimentares que os que foram mencionados na } \\
\text { música. Para isso a professora perguntava, aleatoriamente, se eles } \\
\text { gostavam de cada um dos alimentos mencionados na música e eles } \\
\text { tinham que responder somente com "sim/não". }\end{array}$ \\
\hline 5 & $\begin{array}{l}\text { Oral e escrito } \\
\text { Estruturado } \\
\text { afetivo }\end{array}$ & $\begin{array}{l}\text { Os alunos tinham que preencher uma ficha com seus gostos pessoais } \\
\text { sobre os tópicos expressos na música, marcando "sim" ou "não" ao } \\
\text { lado de cada pergunta (por exemplo, ¿Te gustan las hamburguesas? } \\
\text { [Tu gostas de hambúrguer? Você gosta de hambúrguer?*]). }\end{array}$ \\
\hline 6 & Oral e escrito & $\begin{array}{l}\text { A professora leu uma parte da música Me gustas tú, de Mano Chao, } \\
\text { e fez algumas perguntas de compreensão oral, sem requerer a } \\
\text { produção do verbo-alvo. }\end{array}$ \\
\hline 7 & $\begin{array}{l}\text { Oral e escrito } \\
\text { Estruturado } \\
\text { referencial }\end{array}$ & $\begin{array}{l}\text { Os alunos tinham que preencher uma ficha com os gostos pessoais } \\
\text { expressos na música lida, marcando "sim" ou "não" ao lado de cada } \\
\text { pergunta (por exemplo, ¿Le gusta viajar? Ele gosta de viajar?). }\end{array}$ \\
\hline 8 & $\begin{array}{l}\text { Oral e escrito } \\
\text { Estruturado } \\
\text { referencial }\end{array}$ & $\begin{array}{l}\text { A professora leu e entregou uma folha com uma lista de gostos de } \\
\text { uma personagem fictícia. Novamente, os alunos deveriam responder } \\
\text { às perguntas, indicando qual era a causa do gosto (por exemplo, } \\
\text { na folha havia a frase Las montañas no le gustan [Ela não gosta } \\
\text { de montanhas] e a pergunta era Qué no le gustan [Do que ela não } \\
\text { gosta])? }\end{array}$ \\
\hline 9 & $\begin{array}{l}\text { Oral e escrito } \\
\text { Estruturado } \\
\text { afetivo }\end{array}$ & $\begin{array}{l}\text { Os alunos tinham que preencher uma ficha com seus gostos pessoais, } \\
\text { sobre diversos tópicos, marcando um "x" na coluna correspondente } \\
\text { que aparecia ao lado de cada pergunta (por exemplo, ¿Te gusta el } \\
\text { fútbol? [Tu gostas de futebol? Você gosta de futebol?]). Numa coluna } \\
\text { aparecia uma carinha feliz J, representando "sim" e na outra coluna } \\
\text { havia uma carinha triste L, representando "não"). }\end{array}$ \\
\hline
\end{tabular}

* Incluímos a tradução literal com o pronome "tu" e a outra estrutura equivalente com o pronome você.
Cabe mencionar também que, ao fazer as correções, de modo oral, a professora sempre repetia a frase completa, contendo o verbo-alvo, que poderia servir de input auditivo. A instrução sobre os usos do verbo não se baseou, portanto, em explicações metalinguísticas, mas, sim, em expor, oralmente e por escrito no quadro, as combinações de cada flexão verbal com o seu sujeito, à medida que iam aparecendo nas atividades. Cabe lembrar que essa instrução foi aplicada somente ao grupo experimental.

\section{Análise dos dados e discussão dos resultados}

Inicialmente, é preciso mencionar que os dados foram tabulados e submetidos a análises estatísticas no SPSS 18. Foram realizadas análises descritivas, exploratórias e inferenciais ${ }^{26}$, com base nas orientações de Field (2009) e Martins (2011), comparando os resultados de pré- e pósteste dos dois grupos (experimental e controle), tanto no modo intrasujeitos quanto intersujeitos. Também foram feitas comparações dos resultados das três etapas de testes do grupo experimental. Em seguida, vamos expor os resultados obtidos no pré e pós-teste e, depois, especificamente a evolução do grupo experimental.

\subsection{Resultados do pré- e pós-teste dos grupos controle e experimental}

As análises exploratórias realizadas com os testes de KolmogorovSmirnov e Shapiro-Wilk apontaram que a amostra não estava numa distribuição normal, de modo que foram realizados testes não paramétricos para comparação de médias. A Tabela 1 sintetiza os resultados dos grupos.

${ }^{26}$ As análises descritivas e exploratórias possibilitaram identificar as médias e desvio-padrão dos participantes em cada teste e a normalidade da amostra, para, a partir disso definir os testes inferenciais mais adequados para fazer as comparações de médias e verificar se havia diferenças estatisticamente significativas nos resultados. 
Tabela 1- Resultados gerais de média e desvio padrão dos grupos

\begin{tabular}{lccccc} 
& \multicolumn{2}{c}{$\begin{array}{c}\text { Grupo experimental } \\
\text { N=8 }\end{array}$} & \multicolumn{2}{c}{$\begin{array}{c}\text { Grupo controle } \\
\text { T=11 }\end{array}$} \\
\cline { 2 - 5 } & $\begin{array}{c}\text { Pré-teste } \\
\text { Média } \\
\text { (DP) }\end{array}$ & $\begin{array}{c}\text { Pós-teste } \\
\text { Média } \\
\text { (DP) }\end{array}$ & $\begin{array}{c}\text { Pré-teste } \\
\text { Média } \\
\text { (DP) }\end{array}$ & $\begin{array}{c}\text { Pós-teste } \\
\text { Média } \\
\text { (DP) }\end{array}$ \\
Julgamento de gramaticalidade (N=6) & 3,5 & 3,63 & 3,45 & 3,18 \\
& $(0,75)$ & $(1,18)$ & $(1,03)$ & $(1,53)$ \\
Identificação do sujeito (N=12) & 3,38 & 2,62 & 3,27 & 2,64 \\
Produção de frases (N=5) & $(1,92)$ & $(2,13)$ & $(2,79)$ & $(1,36)$ \\
& 0,75 & 0,62 & 1,18 & 1,27 \\
& $(1,16)$ & $(1,18)$ & $(0,75)$ & $(1,27)$ \\
\hline
\end{tabular}

Conforme exposto na Tabela 1, nas tarefas de julgamento de gramaticalidade, as maiores médias de acertos foram do grupo experimental, nas duas etapas de testes, sendo que, no pós-teste, este grupo aumentou ainda mais o seu escore (de $M=3,5$ no pré-teste para $M=3,63$ no pós-teste), ao passo que o grupo controle diminuiu (de $M=3,45$ no pré- para $M=3,18$ no pós-teste). Note-se que em ambos os grupos o desvio padrão também apresentou aumento $(\mathrm{DP}=0,75$, no pré-teste e $\mathrm{DP}=1,18$, no pós-teste, no grupo experimental; $\mathrm{DP}=1,03$, no pré-teste e $\mathrm{DP}=1,53$, no pós-teste, no grupo controle). Cabe mencionar que a menor a variação no desvio padrão significa que o comportamento dos participantes é mais semelhante, ou seja, mais homogêneo é o resultado.

Por sua vez, nas tarefas de identificação do sujeito das frases, as maiores médias de acertos dos dois grupos foram no pré-teste $(M=3,38$, no grupo experimental e $\mathrm{M}=3,27$, no grupo controle). Observamos que, além da diminuição das médias dos dois grupos, no pós-teste, o grupo experimental aumentou seu desvio padrão (de $\mathrm{DP}=1,92$, no pré-teste para $\mathrm{DP}=2,13$, no pós-teste), mas o grupo controle o diminuiu (de $\mathrm{DP}=2,79$, no pré-teste para $\mathrm{DP}=1,36$, no pós-teste)
Na produção de frases, as maiores médias de acertos foram do grupo controle, nas duas etapas de testes. Além disso, pode-se observar que o grupo experimental diminuiu um pouco seu escore (de $\mathrm{M}=0,75$ no pré-teste para $M=0,62$ no pós-teste), enquanto o grupo controle aumentou (de $M=1,18$ no pré-teste para $M=1,27$ no pós-teste).

Em geral, portanto, houve aumento dos escores no pós-teste do grupo experimental somente nas tarefas de julgamento de gramaticalidade e, no grupo controle, somente na produção. Entretanto, nas comparações de médias de pré e pós-teste, feitas através de testes de Mann-Whitney, não foram identificadas diferenças significativas entre os grupos em nenhuma das três tarefas. Tampouco foram constatadas, nos testes de Wilcoxon, diferenças significativas entre pré e pós-teste, internamente entre os sujeitos de cada grupo (intrasujeitos).

Gráfico 1 - Resultados gerais de média e desvio padrão dos grupos

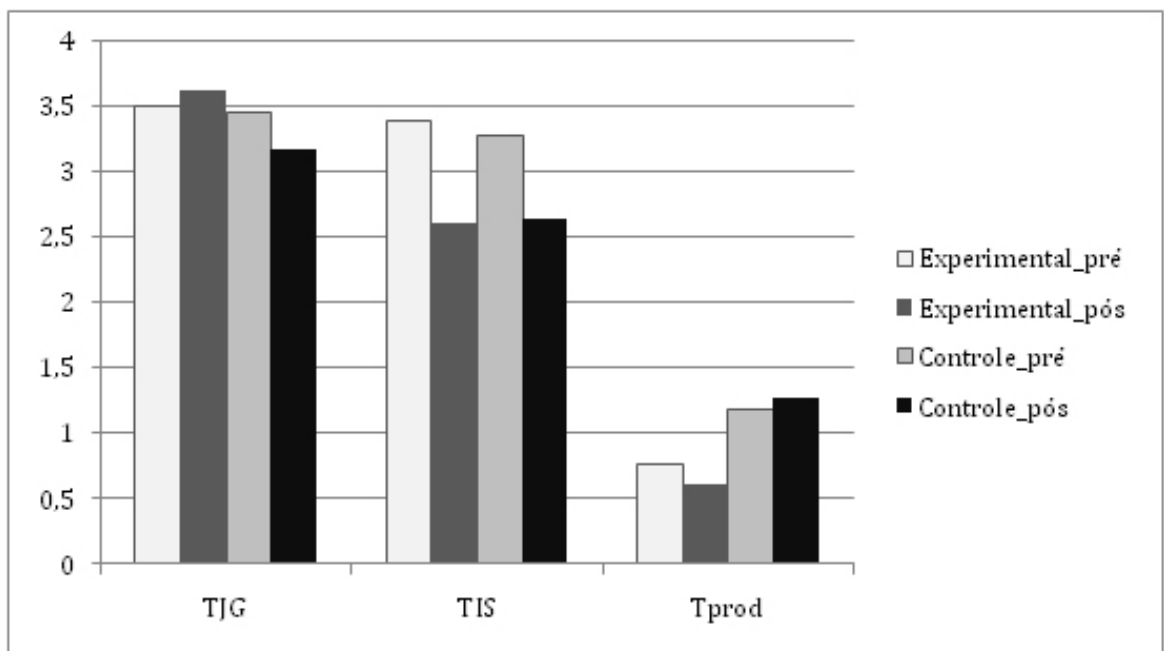

TJG: Tarefa de Julgamento de gramaticalidade; TIS: Tarefa de identificação do sujeito; Tprod: Tarefa de produção de frases. 
Em vista disso, ponderou-se que a instrução de processamento parece não ter aportado vantagem ao processo de aquisição do verbo "gostar", conforme ilustra o Gráfico 1.

O gráfico possibilita visualizar que o grupo experimental apresentou melhor desempenho que o grupo controle no pós-teste na tarefa de julgamento de gramaticalidade. Isso mostra que a oferta de input estruturado talvez tenha contribuído para uma sutil mudança na sensibilização dos aprendizes desse grupo para a gramaticalidade de sentenças com o verbo "gostar".

Pelo exposto até aqui, este estudo parece não corroborar outras pesquisas que apresentaram resultados favoráveis à instrução de processamento (VANPATTEN e CADIERNO, 1993, CADIERNO, 1995; VANPATTEN e SANZ, 1995; CADIERNO, 2010). Entretanto, uma possível explicação para esses resultados talvez seja a pouca ocorrência de explicação gramatical sobre as tendências de processamento que os aprendizes deveriam evitar. Conforme expusemos na descrição da instrução de processamento, enfocamos especificamente a oferta de input estruturado, como em um dos grupos da pesquisa desenvolvida por VanPatten e Oikkenon (1996), mas não obtivemos os mesmos resultados que eles quanto aos benefícios da instrução de processamento. Em vista disso, propôs-se a realização de um segundo pósteste, após um período de instrução na modalidade tradicional. Dessa nova etapa de teste somente o grupo experimental pôde participar, conforme mencionado anteriormente.

\subsection{Evolução do grupo experimental nas três etapas de testes}

Na Tabela 2, sintetizamos os resultados de média e desvio padrão do grupo experimental no pré-teste, no pós-teste e no pós-teste 2 . Com isso, podemos verificar os efeitos da instrução de processamento e da instrução tradicional.
Tabela 2 - Evolução do desempenho do grupo experimental

\begin{tabular}{|l|c|c|c}
\hline \multicolumn{1}{c|}{ Tarefa } & $\begin{array}{c}\text { Pré-teste } \\
\text { Média } \\
\text { (DP) }\end{array}$ & $\begin{array}{c}\text { Pós-teste } \\
\text { Média } \\
\text { (DP) }\end{array}$ & $\begin{array}{c}\text { Pós-teste 2 } \\
\text { Média } \\
\text { (DP) }\end{array}$ \\
\hline Julgamento de gramaticalidade (N=6) & 3,5 & 3,63 & 4,29 \\
Identificação do sujeito (N=12) & $(0,75)$ & $(1,18)$ & $(1,11)$ \\
& 3,38 & 2,62 & 4,43 \\
Produção de frases (N=5) & $(1,92)$ & $(2,13)$ & $(0,97)$ \\
& 0,75 & 0,62 & 2,57 \\
& $(1,16)$ & $(1,18)$ & $(0,97)$ \\
\hline
\end{tabular}

Observamos que, nas tarefas de julgamento de gramaticalidade, houve um aumento progressivo das médias ao longo do tempo, sendo bem expressivo após a instrução tradicional (de $M=3,5$, no pré-teste para $M=4,29$, no pós-teste 2).

Nas tarefas de identificação do sujeito das frases, há uma oscilação no desempenho, com a diminuição das médias na coleta após a instrução de processamento $(M=2,62)$, e um grande aumento no pós-teste $2(M=4,43)$ aliado a uma diminuição do desvio padrão $(\mathrm{DP}=0,97)$, o que significa que o comportamento dos participantes foi mais parecido do que nos testes precedentes.

Na produção de frases, houve uma queda na média do pós-teste $(M=0,62)$, mas um aumento expressivo após a instrução tradicional que precedeu o pós-teste $2(M=2,57)$. Além disso, o desvio padrão também diminuiu $(\mathrm{DP}=0,97)$, ou seja, em termos de produção, os participantes apresentaram desempenhos mais parecidos.

Novamente testes de Kolmogorov-Smirnov e Shapiro-Wilk apontaram que a amostra não estava numa distribuição normal, de modo que foram realizados testes não paramétricos para comparação das médias. Testes de Friedman evidenciaram diferença significativa nas médias dos três testes (pré-teste, pós-teste e pós-teste 2$)\left(\chi^{2}(8)=31,476, p=0,000\right)$ somente nas 
tarefas de produção de frases $\left(\chi^{2}(2)=7,143, p=0,028\right)$. Por isso, realizamos Testes de Wilcoxon e constatamos que essas diferenças significativas se referiam às comparações entre as médias do pós-teste 2 e do pré-teste $(\mathrm{z}=-2,124, \mathrm{p}=0,034)$ e entre o pós-teste 2 e o pós-teste $(\mathrm{z}=-2,032, \mathrm{p}=0,042)$.

Consideramos que esses resultados se devem à combinação dos efeitos da instrução tradicional e da instrução de processamento, ou seja, mostram que o uso de input estruturado e de explicação gramatical pode ser bastante positivo ${ }^{27}$ para o processo de aquisição de L2. Entretanto, para uma interpretação mais abrangente dos resultados, seria importante fazer a comparação com o grupo controle que também receberia instrução tradicional, mas isso não foi possível.

Porém, cabe destacar que dentro de uma abordagem de instrução de processamento é possível oferecer explicação gramatical sobre a formaalvo e dar instrução sobre estratégias de processamento. Mas consideramos que esses dois aspectos foram pouco contemplados na primeira etapa do nosso estudo. Por outro lado, acreditamos que nossa pesquisa evidencia que uma intervenção pedagógica que congregue procedimentos de instrução tradicional e da instrução de processamento, o que é perfeitamente possível, pode ser muito benéfica ao processo de ensino-aprendizagem de línguas.

O Gráfico 2 ilustra os resultados do processo após a aplicação dos dois tipos de instrução sobre o verbo "gostar".

0 gráfico mostra claramente o aumento das médias no pós-teste 2 , de forma mais acentuada nas tarefas de identificação de sujeito e de produção. Coincidentemente, em tais tarefas houve redução no número de acertos no pós-teste. Em vista disso, consideramos que somente a instrução de

${ }^{27}$ Positivo no sentido de propiciar o aumento no número de acertos nas tarefas com o verbo gostar podendo ser um indício de mais aprendizagem da estrutura.
Gráfico 2 - Evolução do desempenho do grupo experimental

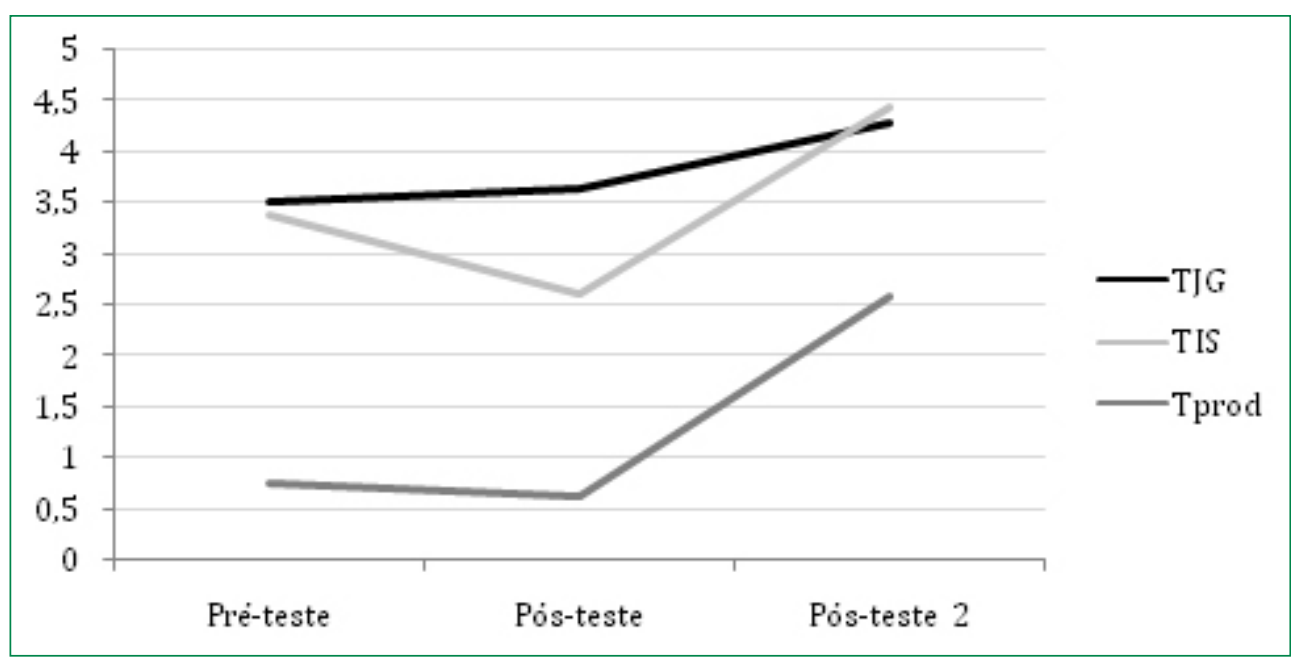

TJG: Tarefa de Julgamento de gramaticalidade; TIS: Tarefa de identificação do sujeito; Tprod: Tarefa de produção de frases.

processamento não foi capaz de surtir efeitos importantes na aprendizagem do verbo "gostar" em espanhol, mas combinada com a instrução tradicional pôde contribuir significativamente com o processo.

\section{Considerações finais}

Neste artigo, apresentamos uma pesquisa que teve como objetivo verificar efeitos da instrução de processamento para aprendizes brasileiros sobre os usos do verbo "gostar" em espanhol. A estrutura desse verbo, além de apresentar importantes distinções entre a L1 e a L2 dos participantes, também pode ser problemática, considerando-se o princípio 2 (do primeiro [pro]nome) do modelo de processamento do input (VANPATTEN, 2005), exposto anteriormente, referente a uma estratégia que leva os 
aprendizes a compreenderem como sujeito o que seria o objeto da frase em espanhol.

Em vista disso, preparamos uma intervenção pedagógica, priorizando atividades com input estruturado, sem exercícios de produção da estruturaalvo e a aplicamos em um grupo experimental. Como percebemos que não houve diferença significativa de desempenho nas tarefas de compreensão (julgamento de gramaticalidade e identificação de sujeito) e de produção entre o grupo que recebeu a instrução de processamento (grupo experimental) e o grupo controle (que não recebeu nenhuma instrução), decidimos realizar uma nova etapa de teste (pós-teste 2). Essa nova etapa aconteceu após a realização da instrução tradicional, mas somente com o grupo experimental.

Os resultados do pós-teste 2 mostraram que houve diferenças significativas nas comparações entre os três testes, especificamente na produção. Esses resultados podem derivar da instrução tradicional. Entretanto, ponderamos que essas diferenças sejam devido à combinação dos dois tipos de instrução, porque as médias nas tarefas de compreensão também aumentaram bastante no pós-teste 2. Mas, infelizmente, não temos um parâmetro de comparação com o grupo controle que só receberia instrução tradicional.

Avaliamos que, talvez, nosso estudo não comprovou vantagens específicas da instrução de processamento porque podem ter faltado mais explicações sobre as estratégias de processamento relacionadas com o princípio 2, para ajudar aos aprendizes a evitar considerar como sujeito o primeiro (pro) nome da frase e melhorar suas habilidades de compreensão. Além disso, a instrução de processamento poderia ter sido oferecida por mais tempo, para dar mais destaque à forma-alvo, tanto através de input visual quanto auditivo.

Consideramos, portanto, necessária a realização de mais estudos que busquem uma amostra maior e que ofereçam uma instrução de processamento mais duradoura, com mais ênfase aos mecanismos de processamento envolvidos e com possibilidades iguais de comparação entre os grupos controle e experimental.

\section{Referências}

ABIO, Gonzalo. Me llamo Pedro y me duele la cabeza no es lo mismo ni da igual. Presentación de los verbos con pronombre en los libros de E/LE para brasileños. In: Anais do I Congresso Nordestino de Espanhol. Recife: Editora Universitária da UFPE, 2008. p. 165-177.

BADDELEY, A; ANDERSON, M. C.; EYSENCK, M. W. Memória. Porto Alegre: Artmed, 2011. CADIERNO, Teresa. El aprendizaje y la enseñanza de la gramática en el español como segunda lengua. Marco ELE: Revista de Didáctica ELE, n.10. p. 1-18, 2010,

CADIERNO, Teresa. Formal instruction from a processing perspective: An investigation into the Spanish past tense. The Modern Language Journal, v. 79, n. 2, p. 179-193, 1995.

CAMPOS, Héctor. Transitividad e intransitividad. In: BOSQUE MUÑOZ, Ignacio; DEMONTE BARRETO, Violeta (Dir.). Gramática descriptiva de la lengua española. Tomo

2. Las Construcciones sintácticas fundamentales: relaciones temporales, aspectuales y modales. Madrid: Espasa Calpe, 2000. p. 1519-1574.

CANÇADO, Márcia, Verbos psicológicos: uma classe relevante gramaticalmente? Veredas, v. 16, n. 2, p.1-18, 2012.

COLUCCIELLO, Mariarosaria. Los verbos psicológicos en español e italiano. Cultura Latinoamericana, v. 22, n. 2, p. 97-115, 2015.

DELBECQUE, Nicole; LAMIROY, Béatrice. La subordinación sustantiva: Las subordinadas enunciativas en los complementos verbales. In: BOSQUE MUÑOZ, Ignacio; DEMONTE BARRETO, Violeta (Dir.). Gramática descriptiva de la lengua española. Tomo 2. Las Construcciones sintácticas fundamentales: relaciones temporales, aspectuales y modales. Madrid: Espasa Calpe, 2000. p.1965-2082.

DOUGHTY, Catherine; WILLIAMS, Jessica (Ed.). Focus on Form in Classroom Second Language Acquisition. Cambridge, MA: CUP, 1998.

ELLIS, Rod. Language teaching research \& language pedagogy. Oxford: Wiley-Blackwell, 2012. 
ELLIS, Rod. La adquisición de segundas lenguas en un contexto de enseñanza: análisis de las investigaciones existentes. Auckland: Ministry of Education, New Zealand, 2005. Disponível em: <http://www.mecd.gob.es/dctm/redele/Material-RedEle/ Biblioteca/2006_BV_05/2006_BV_05_04Ellis.pdf?documentId=0901e72b80e3a029>. Acesso em 24 jan 2017.

ELLIS, Rod. Teaching and Research: Options in Grammar Teaching. TESOL Quarterly, v. 32, n. 1, p. 39-60, 1998.

FIELD, Andy. Descobrindo a estatística usando o SPSS. Porto Alegre: Artmed, 2009.

FINGER, I.; ORTIZ-PREUSS, Elena. Atenção ao input e aprendizagem: o papel da instrução explícita na aquisição do espanhol como L2. Letras de Hoje, Porto Alegre, v. 44, n. 3, p. 78-85, 2009.

GASS, Susan; SELINKER, Larry. Second Language acquisition: an introductory course. 3. ed. New York: Routledge, 2008.

MARTINS, Carla. Manual de análise de dados quantitativos com recurso ao IBM SPSS: saber decidir, fazer, interpretar e redigir. Braga: Psiquilibrios Edições, 2011.

MIOTO, Carlos; SILVA, Maria Cristina Figueiredo; LOPES, Ruth Elizabeth Vasconcellos. Novo manual de sintaxe. Florianópolis: Insular, 2004.

ORTEGA, Lourdes. Understanding second language acquisition. New York, Routledge, 2013.

ORTIZ-PREUSS, Elena; SANZ, Cristina. Aquisição de L2: Interação entre variáveis externas e internas. In: ORTIZ-PREUSS, Elena; COUTO, Elza K. N. N. do; RAMOS, Rui M. do (Org.). Múltiplos olhares e linguística e linguística aplicada. Campinas: Pontes, 2016. p. 121-134.

REAL ACADEMIA ESPAÑOLA; Asociación de Academias de la Lengua Española. Nueva Gramática de la lengua española - Manual. Madrid: Espasa Libros, 2010.

SANZ, Cristina. Adult SLA: The interaction between external and internal factors. In: SANZ, C. (Ed.). Mind and Context in adult second language acquisition: methods, theory, and practice. Washington DC: GUP, 2005. p. 3-20.

SCHMIDT, Richard. Attention. In: ROBINSON, Peter (Ed.). Cognition and second language instruction. Cambridge University Press, 2001. p. 3-32.

SOARES, Eduardo Correa; MENUZZI, Sérgio de Moura. Introduzindo e problematizando papéis temáticos e hierarquias temáticas: uma questão de interfaces. Signo, v. 35, n. 59. Santa Cruz do Sul: EdUNISC, 2010. p. 13-43.
VANPATTEN, Bill. Processing instruction. In: SANZ, Cristina (Ed.). Mind and Context in adult second language acquisition: methods, theory, and practice. Washington DC: GUP, 2005. p. 267-281.

VANPATTEN, Bill. Processing Instruction: An Update. Language Learning, v. 52, n. 4 , p. 755-803, 2002.

VANPATTEN, Bill. Input Processing and Grammar Instruction in Second Language Acquisition. Ablex Publishing Corporation: New Jersey, 1996.

VANPATTEN, Bill.; OIKKENON, Soile. Explanation versus structured input in processing instruction. Studies in Second Language Acquisition. v. 18, n. 4, p. 495-510, 1996.

VANPATTEN, Bill.; SANZ, Cristina. From input to output: Processing instruction and communicative tasks. Second language acquisition theory and pedagogy. 1995. p. $169-185$.

VANPATTEN, Bill.; CADIERNO, Teresa. Input processing and second language acquisition: A role for instruction. The Modern Language Journal. v. 77, n. 1, p. 45-57, 1993.

Recebido em: 25/01/2017

Aceito em: 04/06/2017 